\title{
R3SOLVE: A Serious Game to Support End-of-Life Rooftop Solar Panel Waste Management
}

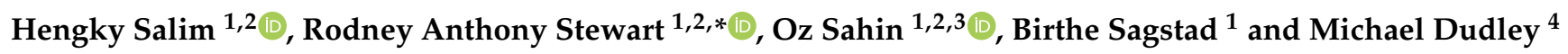 \\ 1 School of Engineering and Built Environment, Griffith University, Southport, QLD 4222, Australia; \\ h.salim@griffith.edu.au (H.S.); o.sahin@griffith.edu.au (O.S.); birthe.sagstad@griffithuni.edu.au (B.S.) \\ 2 Cities Research Institute, Griffith University, Southport, QLD 4222, Australia \\ 3 Griffith Climate Change Response Program, Griffith University, Southport, QLD 4222, Australia \\ 4 TechCollect NZ, Auckland 0642, New Zealand; michael.dudley@anzrp.com.au \\ * Correspondence: r.stewart@griffith.edu.au
}

Citation: Salim, H.; Stewart, R.A.; Sahin, O.; Sagstad, B.; Dudley, M. R3SOLVE: A Serious Game to Support End-of-Life Rooftop Solar Panel Waste Management. Sustainability 2021, 13, 12418. https:/ / doi.org/10.3390/su132212418

Academic Editors: Eran Ben-Elia and Antonis A. Zorpas

Received: 30 July 2021

Accepted: 4 November 2021

Published: 10 November 2021

Publisher's Note: MDPI stays neutral with regard to jurisdictional claims in published maps and institutional affiliations.

Copyright: (c) 2021 by the authors. Licensee MDPI, Basel, Switzerland. This article is an open access article distributed under the terms and conditions of the Creative Commons Attribution (CC BY) license (https:/ / creativecommons.org/licenses/by/ $4.0 /)$.

\begin{abstract}
A complex systems model is necessary to holistically address the end-of-life (EoL) solar panel waste problem. However, there is a significant challenge in communicating such a model to stakeholders. Serious games can overcome this challenge by simplifying a complex model via a user-friendly interface. It enables stakeholders to experiment with different decisions and understand their long-term impacts in a safe environment. In this paper, a serious game called R3SOLVE was designed from a previously developed system dynamics (SD) model. The goal of the game is to achieve certain collection and recovery outcomes through a mix of decisions ranging from product stewardship strategies, landfill regulation, technological investment, promotional effort, reuse strategy, and infrastructure improvement. The game has a single player mode, where a player can access all decisions, and a multiplayer (turn-based) mode, where two players with different roles work collaboratively to achieve the desired outcome. Rewards and penalties also exist in the game to promote players' extrinsic motivation to use critical thinking. Both game modes have been tested in separate workshops to identify bugs and issues regarding goal clarity and in-game information. Future directions to conduct stakeholder workshops and the evaluation approach are also suggested at the end of this paper.
\end{abstract}

Keywords: solar panel; photovoltaic; product stewardship; circular economy; serious game; stakeholder engagement

\section{Introduction}

Enabling a product stewardship scheme and landfill regulations to manage endof-life (EoL) solar photovoltaic (PV) panel waste is critical to prevent negative impacts on the environment and human health [1-3]. Product stewardship is an approach to preventing the potential impacts of a product from the product design to disposal stage by placing physical or financial responsibility on producers, distributors, importers, and/or consumers. This approach aligns strongly with the extended producer responsibility (EPR) principle employed in European countries and the United States to manage different types of waste. A PV product stewardship scheme is currently undergoing an assessment process by the federal government [4]. To mitigate this issue, a system dynamics (SD) model is imperative to holistically analyse different transition pathways and their impacts on the collection and recovery outcomes [1].

Stakeholder engagement (e.g., from government, recycling industries, and PV industries) is an important process in evidence-based research to facilitate knowledge transfer and exchange. However, communicating a complex systems model to stakeholders present political and capability challenges to researchers [5]. A systems model can be highly politicised by stakeholders, where entrenched opposing opinions can lead to a rejection of the ideas and logic presented in the model [6]. Stakeholders often do not possess the 
necessary skills to comprehend and initiate a discussion when presented with a complex mathematical model.

Collaborative tools such as serious games have been increasingly used to make a complex model more accessible to stakeholders [7-9]. Serious games attempt to create an experiential learning environment by simplifying complex models into an immersive and user-friendly interface. It offers stakeholders a safe environment to experiment with different types of decisions and reflect on the outcomes [8,9]. Rodela et al. [10] categorises serious games as learning-based interventions where stakeholders can initiate dialogue and activities to contribute to social learning. In this category, serious games are described as a participatory tool for engaging with certain groups of people for practical or behavioural changes. A well-designed intervention-based serious game can bridge between science and practical decision-making activities as well as conveying real-world system complexities [8]. It allows stakeholders to explore and integrate new ideas and solutions through collaborative exploration of 'what-if' scenarios [11,12]. van Hardeveld, et al. [8] argued that serious games can support collaborative management strategies, improve understanding, and enhance cooperation among stakeholders.

Developing a serious game for managing EoL PV panels is imperative to assist its ongoing PV product stewardship assessment process [1] by increasing scientific understanding of the decision-makers involved, thus informing and assisting their scheme design and funding model. It also helps stakeholders with conflict management [13] as the systems studied have conflicting economic, environmental and social objectives [14]. In this paper, a serious game called R3SOLVE (Resource Recovery for Residential Solar-Virtual Environment) was developed based on an SD model for the purpose of future stakeholder engagement. As pointed out by Flood et al. [15], capturing complexity and long-term uncertainties are two of the main challenges in designing a serious game. Incorporating the SD model helps the game to capture the interactions between different system elements and long-term dynamic behaviour [16]. The game was designed as a card game and incorporated both single player and multiplayer (turn-based) modes.

This paper is limited to describing the overall process of serious game development, which involves developing a knowledge elicitation engine (KEE), user interface, and the description of learning objectives, game architecture, design elements, and game mechanics. The analysis and conceptualisation were conducted prior to designing the serious game to ensure that the learning objectives are relevant and that the game design elements and mechanics are engaging and immersive. Two beta testing workshops were performed after the game had been completed to identify bugs and gain some feedbacks. Future directions to evaluate the effectiveness of the serious game in improving stakeholders' decision-making ability were also discussed.

\section{Related Works}

There is a relatively broad application of serious games to support stakeholder learning on sustainability decision-making $[17,18]$. Table 1 reviews selected literature focused on developing a computer-based serious game (excluding virtual reality and augmented reality games) for sustainability to support stakeholder engagement and learning. These types of serious games primarily focused on water management and planning, with a few games addressing trans-disciplinary environmental problems.

None of the existing literature has developed a computer-based game to support the design of a product stewardship scheme and other strategies for managing PV panel waste. Waste management-related serious games were also mainly targeted at educational purposes rather than stakeholder learning [19-22]. As suggested by Rodela et al. [10], a serious game must be able to convey the pedagogical principles through its interface. An SD model-based serious game for the purpose of stakeholder engagement should use a simple and intuitive user interface to retain the pedagogy related to system complexity and dynamics as opposed to a complex 3D environment which focus largely on edutainment [23]. 
Table 1. Selected serious games for stakeholder learning on sustainability.

\begin{tabular}{|c|c|c|}
\hline Author & Game Title & Game Description \\
\hline Bassi et al. [23] & WATERSTORY ILE & $\begin{array}{l}\text { Require players to simulate the impacts of different policy } \\
\text { interventions on water demand and supply. }\end{array}$ \\
\hline Richards et al. [24] & SESAMME & $\begin{array}{c}\text { The game aims to assist researchers to elicit collective } \\
\text { knowledge regarding specific socio-ecological problems in } \\
\text { coral reefs and related ecosystem services from } \\
\text { community members. }\end{array}$ \\
\hline Savic et al. [13] & SeGWADE & $\begin{array}{l}\text { Requires players to analyse, design, and evaluate a least-cost } \\
\text { water distribution system. }\end{array}$ \\
\hline Khoury et al. [25] & - & $\begin{array}{l}\text { Focuses on flood mitigation that allows players to change the } \\
\text { level of investment in drainage infrastructures and the type of } \\
\text { farming system and to see the resulting flood impacts and } \\
\text { management costs. }\end{array}$ \\
\hline Craven et al. [26] & SimBasin & $\begin{array}{l}\text { Players must select projects that affect the future of the river } \\
\text { basin, such as hydropower, ecological restorations, or flood } \\
\text { protection dikes. }\end{array}$ \\
\hline Sušnik et al. [7] & SIM4NEXUS & $\begin{array}{l}\text { Players will implement policy interventions across } \\
\text { water-food-land-energy-climate nexus and reflect on the } \\
\text { implications and synergies for } 12 \text { multi-scale case studies } \\
\text { ranging from regional to global. }\end{array}$ \\
\hline van Hardeveld et al. [8] & RE:PEAT & $\begin{array}{c}\text { The game aims to promote collaborative management of } \\
\text { peatlands, including the accurate assessment of site-specific } \\
\text { impacts and facilitate negotiation processes on goals, means, } \\
\text { and implementation pathways. }\end{array}$ \\
\hline den Haan et al. [9] & Virtual River Game & $\begin{array}{l}\text { Players collaboratively experiment with river management } \\
\text { options and understand the implications and trade-offs on } \\
\text { physical system. }\end{array}$ \\
\hline Neset et al. [27] & Climate Adaptation Game & $\begin{array}{c}\text { Players will play the role of the chairman of the city council } \\
\text { and be challenged with several urban planning and } \\
\text { development missions whilst promoting climate change } \\
\text { adaptation strategies. }\end{array}$ \\
\hline Neset et al. [28] & Maladaptation Game & $\begin{array}{l}\text { Players will go through four challenges in which they have to } \\
\text { implement different adaptation measures and explore the } \\
\text { potential maladaptive outcomes. }\end{array}$ \\
\hline Teague et al. [29] & Multi-Hazard Tournament & $\begin{array}{l}\text { Players will evaluate different adaptation options and } \\
\text { mitigate various water-related hazards such as flood, drought, } \\
\text { and water pollution. }\end{array}$ \\
\hline
\end{tabular}

Although most of these computer games have successfully captured the dynamic behaviour of the system under study, they are lacking consideration of a multiplayer mode that allows player to take different roles to collaboratively take actions and achieve the goals. A multiplayer game is imperative in the context of engaging with stakeholders in PV waste management to enable social learning due to the multi-actor nature of the system [30]. This game mode can facilitate communication, negotiation, and discussions, which often take place during the policy assessment and design process.

\section{Material and Methods}

This study followed the serious game development process by van Daalen et al. [31] and Sušnik et al. [7] in converting the SD model into a serious game, including (1) creating the KEE and (2) developing the serious game. The SD model, coupled with a game database system, formed a KEE as a decision support system for the serious game. In developing the serious game, this study extended the aforementioned approach with the integrated process framework proposed by Braad et al. [32]. This framework is useful in identifying 
game elements that are practical and engaging for stakeholders. The framework consists of formative evaluation and summative evaluation, which is cyclical, iterative, and phasic in nature. The focus of this study is on the formative evaluation as it describes the serious game design process, whereas summative evaluation deals with the learning evaluation of the game, which is discussed in the future directions of this research.

\subsection{Knowledge Elicitation Engine}

The SD model was used as part of the KEE to process, simulate, and generate player data [7]. KEE also provides feedbacks to players explaining the multi-faceted consequences of the decisions they have made. The complex structure of the model is encapsulated and simplified into a user interface (UI), so players will learn about this complexity in an implicit manner [31,33]. A game database also forms as part of the KEE which refers to the in-game database that is used to store and retrieve data for the purpose of simulation and visualisations.

\subsubsection{System Dynamics Model}

The SD model was developed following the approach by Sterman [16], starting from (1) problem scoping, (2) model conceptualisation, (3) system dynamics model development, and (4) model use and recommendations (Figure 1).
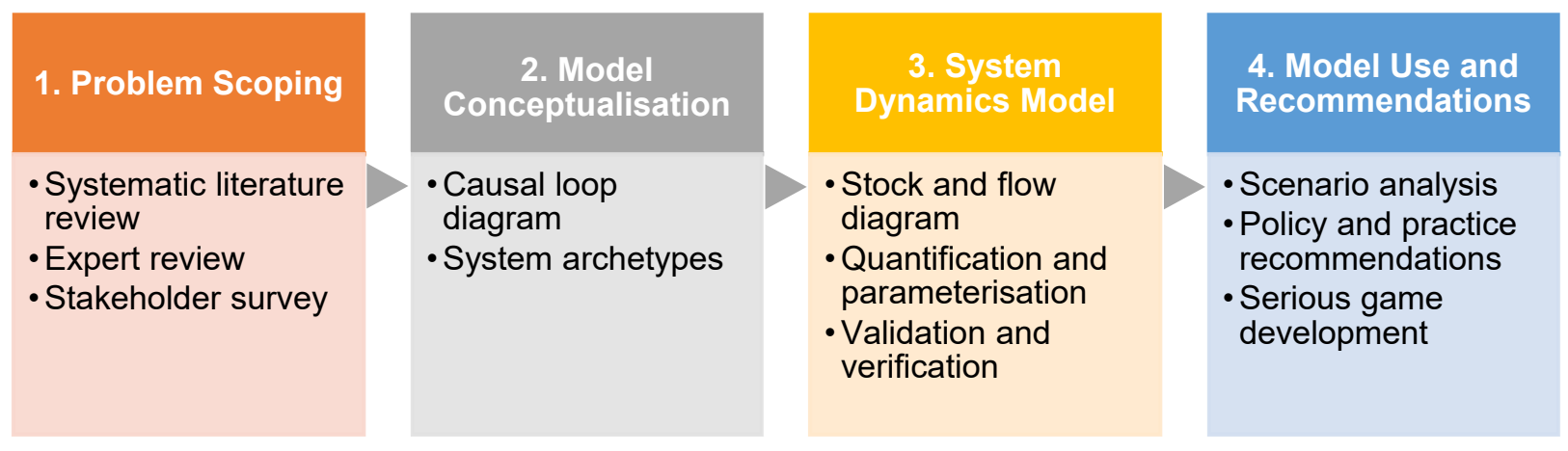

Figure 1. Overview of the system dynamics model development process.

1. Problem scoping: This process served to determine the model boundary, which was conducted through a systematic literature review, expert interviews, and stakeholder surveys. The problem conceptualised in the model is the need to enable a product stewardship scheme, landfill regulations, incentives, and infrastructure development to promote collection and recovery outcomes of PV panel waste [14,34]. The model focused on residential-scale PV panel waste as it accounts for the largest solar energy generation [35]. Commercial-scale and utility-scale solar would have different material flows at the end of lifecycle, especially in the collection and reverse logistics processes [34]. Detailed methodology and results for the problem scoping stage can be viewed in Salim et al. [14].

2. Model conceptualisation: A conceptual model can be developed based on the model boundary and system variables identified from the previous stage. A causal loop diagram (CLD) was used to explain the interrelationship between different subsystems in Salim et al. [1]. The final CLD was composed of seven subsystems, including adoption and waste generation, waste flow, landfill regulation, installers' participation, industry compliance, and government strategies. Detailed methodology and results during the model conceptualisation stage can be viewed in Salim et al. [34] and Salim et al. [1].

3. System dynamics model development: The CLD was translated into a quantitative SD model to explore the dynamic impacts of different product stewardship transition pathways on the collection and recovery outcomes as well as the economic impacts of 
the waste management cost on rooftop PV uptake. Detailed methodology and results of the SD model development can be seen in Salim et al. [1].

3.1. Stock and flow diagram: The stock and flow diagram (SFD) was created using Vensim ${ }^{\circledR}$ DSS to further visualise the system structure that assists with the mathematical equations formulation. The SFD consisted of three subsystems, namely market, collection and recovery, and policies and regulation. The market subsystem captured the dynamics between the rooftop PV uptake, financial motivations, and the internalisation of the waste management cost into the PV cost. The waste flow subsystem depicts two plausible flows of EoL rooftop PV panels, which can either be recycled or reused. The policies and regulations subsystem explored the dynamics between product stewardship scheme and landfill regulations and their impacts on the collection and recovery activities.

3.2. Quantification and parametrisation: The model equations and parameters were manually written using RStudio with the ordinary differential equation (ODE) solver in the deSolve package. Besides the capability limitation of commercially available SD software in employing the Weibull probability function to estimate the waste generated in the market over time [1,2], An R script format also allowed an easier conversion of the model into C\# scripts for the purpose of game development [7]. The SD model runs from 2001 to 2050 with a one-year time step.

3.3. Validation and verification: The model was structurally and behaviourally validated through various techniques outlined by Forrester and Senge [36] to ensure that the model was useful and realistic to stakeholders. A continuous stakeholder engagement approach employed throughout the model development process had helped to increase the model's confidence.

4. Model use and recommendations: The model was then used to explore four transition pathways, namely market-driven growth, conservative development, shared responsibility, and disruptive change against business-as-usual. Policy and practice recommendations can be drawn based on this scenario analysis process. Detailed methodology and results of the scenario analysis can be seen in Salim et al. [1]. The context of the model use also involved the conversion of the SD model into a serious game, which is addressed in this paper.

\subsubsection{Game Database}

The game database was created using the built-in classes in Unity3D such as lists, arrays, dictionaries, etc. The data stored in this repository includes the list of decisions taken by the players, the current game status, and the detailed simulation results. All variables from the SD model and its data and configurations (e.g., time step, minimum and maximum simulation time) were declared in Unity3D's C\# scripts. These player data were used by the KEE to generate further player recommendations and knowledge in a game session [7].

\subsection{Serious Game Development}

This section describes the methods used in the serious game development process. The formative evaluation involves the analysis, concept, design, and quality assurance to identify, confirm, and implement learning objectives and goals, whereas the summative evaluation refers to prototyping, playtesting, and evaluating the game in practice to ensure that the game is fun and insightful [31]. Both single player and multiplayer game modes were developed using the Unity3D game engine using a WebGL build platform. The multiplayer mode also utilised the Photon Unity Networking (PUN) package [37] to enable communication of game objects between players through a server. The advantage of using PUN is its flexibility for developers to adapt its APIs based on different needs and requirements [38]. 


\subsubsection{Analysis and Concept}

Preliminary research on instructional goals and game concept is an important prerequisite of the design phase to deliver an informative and engaging serious game [32]. The analysis stage involves determining the platform for game delivery, target audience, learning the context of the game, the required resources, and the important stakeholders involved in the PV product stewardship scheme development and operationalisation. This was carried out by reviewing pertinent literature on serious game development on environmental management, as outlined in Section 2, with a consideration into the model boundary, purpose, and objectives of the developed SD model in the previous research stage.

The conceptualisation stage extended the analysis stage by identifying learning goals and the high-level concept of the gameplay. To determine both aspects, the authors considered the following factors: (1) the purpose of the game, (2) instructional theory, and (3) game elements (e.g., rewards and penalties, player roles and responsibilities, goals of the game, etc.) that support the learning objectives [32]. The concept of this game was largely inspired by the SIM4NEXUS game [7], but also extending some of its elements from SimBasin [26] and the Climate Adaptation Game [27] to better capture the behavioural dynamics over time.

\subsubsection{Design}

According to Mariais et al. [39], the design phase should consist of three elements, including syntax, semantics, and pragmatics. Syntax involves the organisation of game elements or structure, such as sprites, background, charts, structured objects, etc. Designing UI for a serious game is a pragmatic and artistic process, although it needs to consider user inputs to establish an engaging and immersive UI [32], which is discussed in the quality assurance (QA) phase. Semantics element deals with the meaning and interpretation of the game elements. This includes the use of narratives, rewards and penalties, scenario characteristics, decision variables, feedback processes, and complexity progression [40]. Pragmatics refer to the components related to the operationalisation of the game. This involves designing game mechanisms such as mechanisms of cooperation in the multiplayer mode, decisions available for different player roles, C\# scripts to enable communication between the KEE and UI [7,12]. The design aspect must also take into account the duration that players have to spend in a game session [9]. Particularly when the game utilises an SD model with a lengthy simulation duration, the game design should be able to summarise the time step to produce a reasonable game duration.

The SD model was converted into several packages for the game development purpose, such as the model script, simulation configuration script, model parameters script, and JSON data file (Table 2). The transition pathways explored using the SD model in Salim et al. [1] were not integrated into the game as scenarios will be developed by players during the game session.

Table 2. Packages converted from the SD model for game development.

\begin{tabular}{|c|c|}
\hline Package & Description \\
\hline Model script & $\begin{array}{l}\text { To declare variables for storing and retrieving player } \\
\text { and simulation data and to declare the mathematical } \\
\text { equations used in the SD model }\end{array}$ \\
\hline Simulation configuration script & $\begin{array}{l}\text { To declare variables for controlling the time step and } \\
\text { conditions of the simulation }\end{array}$ \\
\hline Model parameters script & $\begin{array}{l}\text { To declare variables for storing and changing the } \\
\text { model parameters }\end{array}$ \\
\hline JSON data file & $\begin{array}{l}\text { Contains time-series data and lookup tables related to } \\
\text { solar installations, unit cost of PV panels, average } \\
\text { capacity of PV panels, and rebates and subsidies }\end{array}$ \\
\hline
\end{tabular}




\subsubsection{Quality Assurance}

There were two processes conducted in the QA process, namely output validation and workshops $[10,26]$. To validate the results presented in the SD simulation, the authors implemented the model parameters in each transition pathway described in Salimm et al. [1] into the game. The simulation results in the game were then compared against the results obtained from the SD model simulation [41]. The SD simulation and game simulation results should produce the same values. Rewards and penalties were also checked to see if they produced realistic scores by running multiple scenarios in the game.

Two internal workshops were conducted to identify bugs and obtain feedback to improve the user experience. Participants consist of academics and PhD students who were working in a field related to systems thinking or multi-disciplinary sustainability research. The first workshop was aimed at identifying bugs for the single player mode. There were three academic staff and four PhD students attending this workshop. Only two of the academic staff had prior experience with product stewardship research. The second workshop was conducted to identify bugs present in the multiplayer mode. There were three academic staff, one PhD student, and one undergraduate student who attended the workshops. Participants were asked to form a pair of two and select a role, either as a government or product stewardship organisation (PSO). Similarly, only two of the academic staff had prior experience in product stewardship research. Participants from both workshops mainly identified bugs related to UI elements that did not work properly and scoring problems due to the high penalties.

Subsequent online workshops were also conducted with 12 experts (e.g., in the field of waste management and environmental policy) and non-experts (e.g., students and industries) to evaluate the overall impressions of the game and the preliminary cognitive and relational learning outcomes from the multiplayer game sessions. These workshops were also useful to further identify bugs and to consider their feedback. The indicators to measure their overall impressions and cognitive and relational learning outcomes were adapted from den Haan et al. [9] using a five-point Likert scale (between -2 to indicate strong disagreement and 2 to indicate strong agreement to each statement).

\section{Results for the Game Development Process}

R3SOLVE is a card-based serious game that can be played as a single player or multiplayer. The gameplay overview of both game modes is depicted in Figure 2. The game can be accessed via web browser publicly via https:/ / www.circularinterplay.com/r3 solve_web/index.html (accessed on 9 July 2021) and is thus compatible across different desktop operating systems (e.g., Windows, MacOS, Linux). Each game session consists of six rounds from 2020 to 2050 with five-year time steps each, which is a further simplification from the SD model simulation time.

\subsection{Learning Objectives}

The learning objectives in model-based serious games would normally align with the problems and solutions being observed in their model(s) $[7,23]$. Thus, this game aims to promote stakeholder (i.e., government at all levels, recycling industries and solar industries) learning on the concept of PV panel product stewardship scheme development and other supporting decisions such as landfill regulation, funding model, reuse strategy, promotions, and other industry responses to the scheme. The impacts observed in the game includes collection and recovery outcomes, landfill waste generation, and consequences of the internalisation of the waste management cost into the product price (i.e., payback period and adoption). 


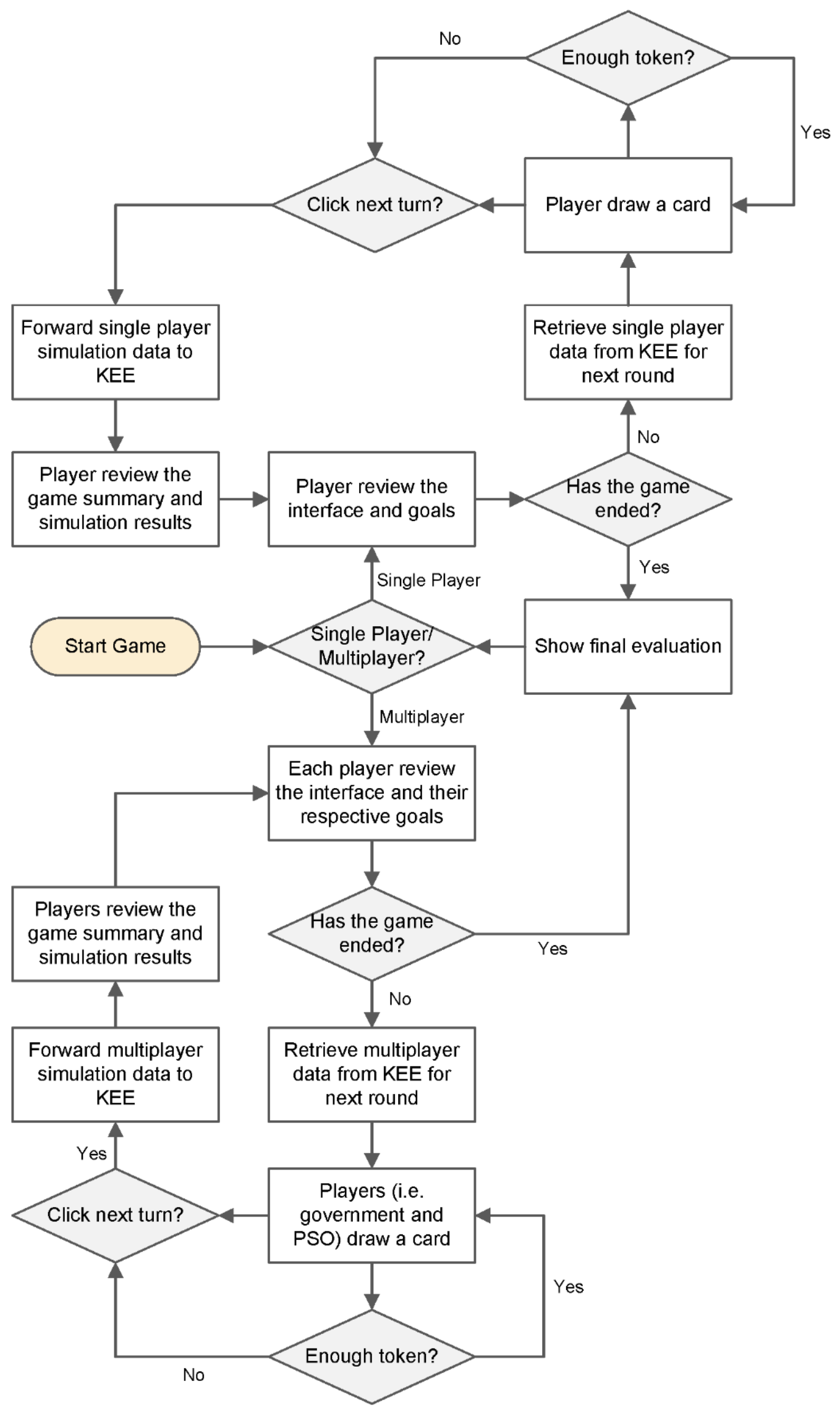

Figure 2. Gameplay flowchart. 
The game consists of a single player and multiplayer mode. The learning objective of the single player mode is to enable a player to understand the interconnectivity and trade-offs between different stakeholder objectives because they are presented with all decisions available for all actors in the PV panel supply chain. The multiplayer feature in this game attempt to fill the existing gap in promoting social learning through serious games. It centres on the idea to enable stakeholders, especially government and PSO, to experiment with collaborative strategies to deal with this waste stream. Thus, stakeholders can understand what decisions, goals, and expectations apply to different roles in the supply chain as well as to learn about the long-term impacts of their decisions.

\subsection{Game Architecture}

The game architecture for R3SOLVE was made up of two components, namely the KEE and the game engine (Figure 3). The design framework by Mariais et al. [39] helped to organise the game objects and visualisations as well to link all the game components together. Detailed descriptions of KEE's components are discussed in the methodology section. KEE communicates with the game through a communication controller, which is a script that allows the model and UI (i.e., game objects and visualisations) to exchange data information. In the multiplayer mode, this communication controller is also supported by PUN to allow information sharing across all clients in a game room.

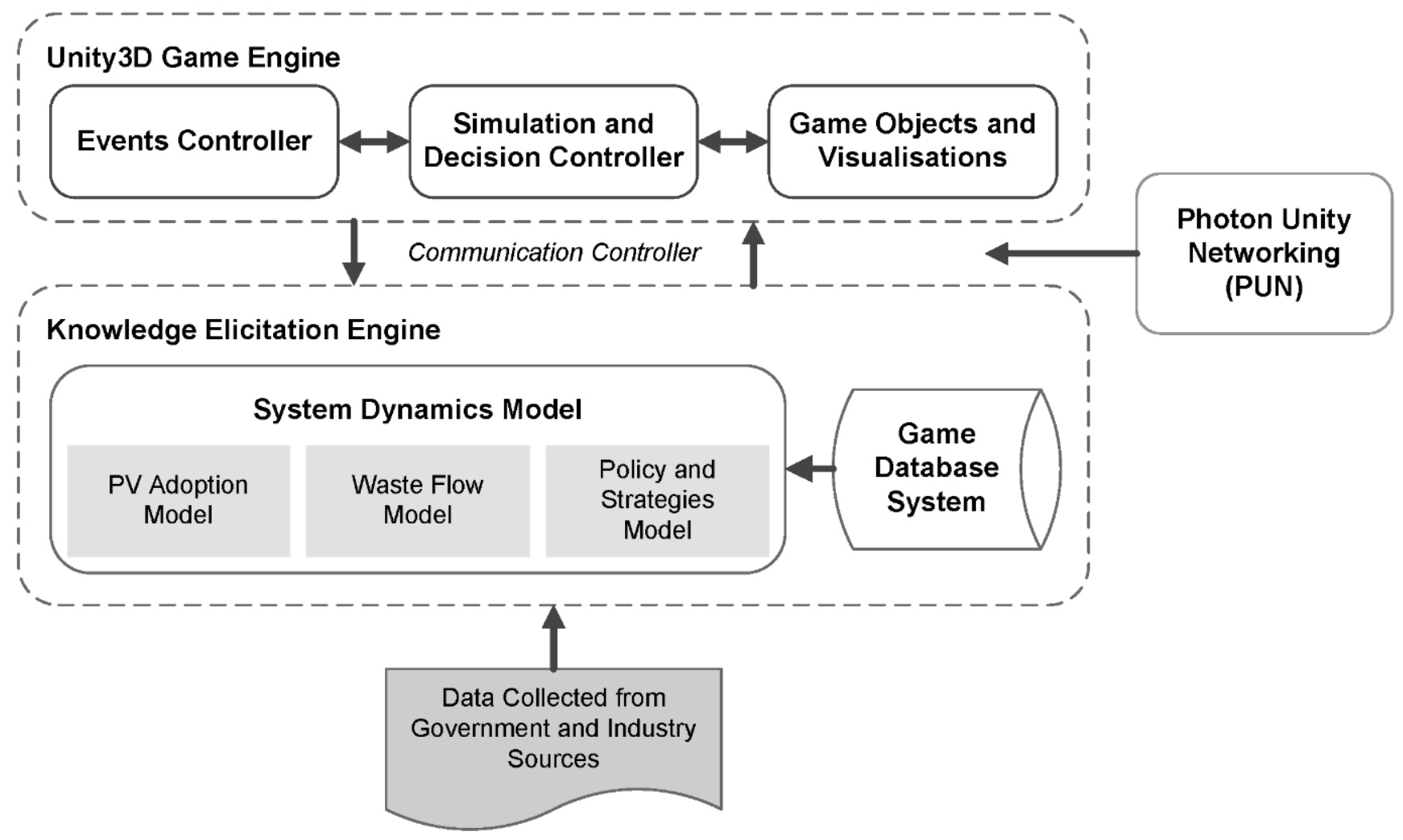

Figure 3. Modular architecture of R3SOLVE.

An events controller was also created as a way of sending events to game objects based on user inputs (e.g., mouse click, drag and drop, and keyboard input) [42]. This controller is also linked with the simulation and decision controller, which is created to enable configuration of simulation and decisions based on user inputs. The simulation and its parameters can be configured by the players through the communication controller. Player data modified and generated from the game will be stored in the game database system in the KEE. 


\subsection{Design Elements}

\subsubsection{Tokens and Social Status}

The game features a token system that indicates the remaining budget to be spent on playing the cards or representation of the economic conditions of each player. A token system is the most used serious game feature to create a better understanding of the limited nature of financial resources in decision-making activities [7,26,27]. Any unallocated token will be used for the subsequent round. Tokens will be added and deducted based on the rewards and penalties discussed in the later sections. This game also features social status value which reflects the public perception of the government and PSO's activities. Social status will keep accumulating by playing different cards until the end of the game. Penalties do not apply to the social status value.

\subsubsection{Decision Cards}

The game does not use predefined scenarios to enable decision experimentation and to offer flexibility to players to choose the stringency and robustness of their strategies so they can reflect on the impacts of regulations and/or strategies at different stringency levels. These decisions were represented by cards that have different properties such as cost, social acceptance, waiting time until the decision is implemented, and the duration of the card. Depending on the game mode selected (i.e., single player or multiplayer), players will have full or partial access to the following decision cards:

1. Product stewardship: Players can select different product stewardship approach (i.e., voluntary, co-regulatory, or mandatory), increasing scheme target, or introducing tax at point of sales.

2. Landfill levy/ban: Landfill levy can be increased at a certain rate or a landfill ban can be implemented.

3. Waste collection improvement: Players can increase their promotional effort to make the scheme more visible to the public, expand the geographical scope of the collection points, and shorten the distance between collection points.

4. Recovery strategies: Players can introduce reuse strategies (i.e., repurposing EoL PV panels with high level efficiency for other applications) and improve material recovery rate (i.e., the amount of materials that can be recovered from a PV panel).

The cost of some decisions is dynamic, depending on the current game status. For example, when players keep expanding the geographical scope of the collection points, the cost of this card will get more expensive over time. This is because investing in waste collection infrastructures in remote areas will be far more expensive than in metropolitan areas.

To play the decision cards, players drag and drop the cards into the decision timeline section. The decision timeline section acts as a temporal summary of the decisions that have been made by the player(s) (i.e., when the decisions will start and end). Players will be presented a detailed description of each decision that they have chosen and the impacts of the decision on the game parameters. Players can also remove the decision cards from the decision timeline for the current round, but they cannot remove the decisions if the cards were placed in the previous rounds.

\subsubsection{Performance Graphs}

This serious game was designed based on a cyclical design, which means players make decisions, take actions, receive the results, draw feedbacks, and proceed to take further actions based on the outcomes [7,43]. After each round has been completed, players are encouraged to review and reflect on the current game summary and simulation results (Figure 4) closely and take the subsequent actions needed to improve their game performance. Besides the pie chart to summarise the current reuse, recycling, and landfill rates, the game summary consists of the model parameters that can be modified through the chosen decisions, such as product stewardship, landfill levy, the geographical scope of collection points, material recovery rate, etc. 
This game uses a performance graph to describe players' performance, which is a gamification technique to provide information regarding a player's performance over-time. The simulation results present six indicators used for the scenario analysis in Salim et al. [1] (i.e., collection fraction, collection rate, total recovered materials, landfill disposal, payback period, and dwellings with PV) and an additional two indicators (i.e., reuse rate and recycling rate) for greater clarity on the breakdown of recovery activities.

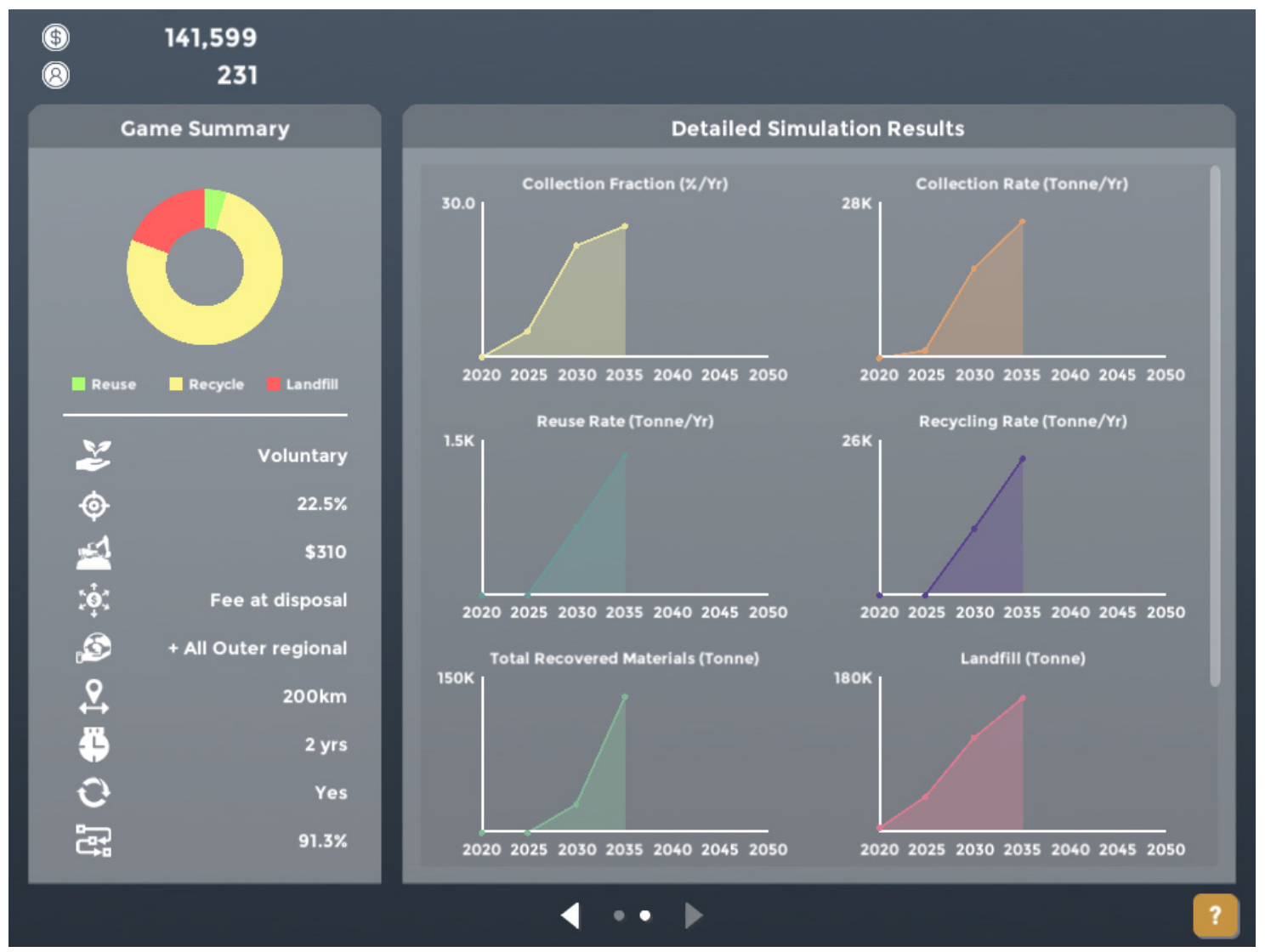

Figure 4. Game summary and detailed simulation results page.

\subsection{Game Mechanics}

\subsubsection{Single Player Mode}

Interface: After selecting the single player mode, the main page of the game will be displayed (Figure 5). Players will be able to reset the game and display the help section to guide them during the gameplay.

Roles and specific goals: The objective is to achieve the best collection and recovery outcomes, minimise landfill disposal, and minimise impacts on the PV uptake. The player will be given 30,000 tokens at the start to be spent on initial decisions. Players must accumulate as many tokens and social status as possible.

Decision-making and simulation: In the single player mode, players can access all the decision cards available within the government and PSO's domains. After completing decisions in each round, players will be warned whether the current collection rate meets the specified scheme target under the "Your Task" box. In this mode, a simple KEE is responsible for simulating the model and storing player data.

Rewards and penalties: Tokens will be added or deducted depending on how the outcomes will trigger the rewards and penalties. Rewards are derived from the amount of PV panels that are recovered (i.e., recycling and reuse), which is calculated using Equation (1). Reuse will result in higher token earning because due to less processing being required to repurpose PV panels. Penalties are triggered because of landfill disposal and as 
a consequence of not meeting the scheme target, which is calculated using Equation (2). If the penalties caused the tokens to enter a negative value, then the system will automatically reset the token to 2000 , so the players can still progress with the game.

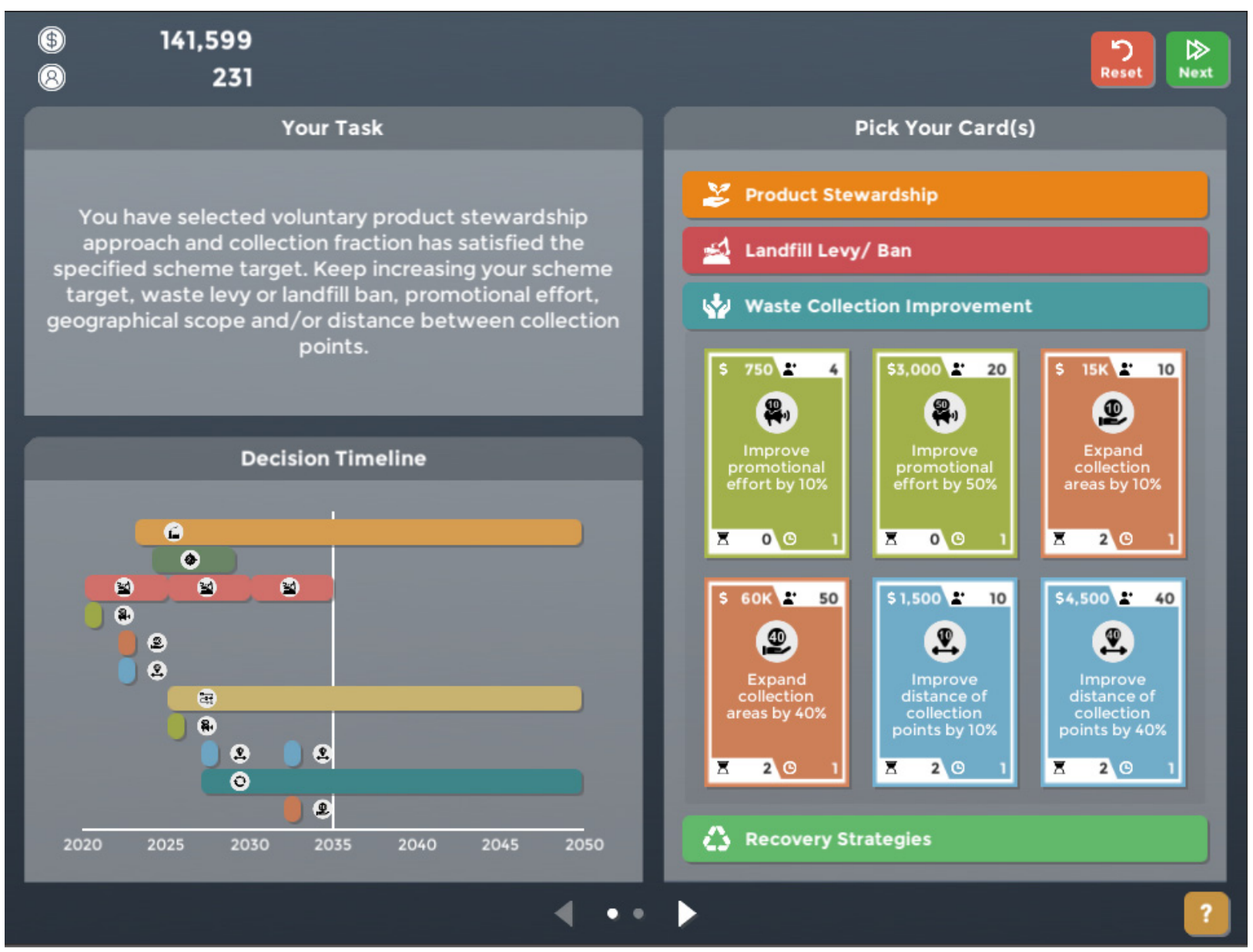

Figure 5. Single player game session-main page.

token earning $=$ recycling rate $\times \frac{50}{\text { time }-20 / 5}+$ reuse rate $\times \frac{75}{\text { time }-20 / 5}$.

token penalty $=$ landfill disposal rate $\times \frac{0.1}{\text { time }-15 / 10}+\frac{\text { collection target }- \text { collection rate }}{80}$

\subsubsection{Multiplayer Mode}

Interface: After selecting the multiplayer mode, each player will enter a lobby and decide whether they want to join an existing room or create a new room. Each room has a unique randomly assigned room code for clients to join in the room created by the host. Upon entering the room, players can decide which role (i.e., government or PSO) they want to play (Figure 6). In this mode, the interface used is similar to the single player mode (Figure 7), although only decisions applicable to each player role will be visible.

Roles and specific goals: One player will play as a government with a specific goal to achieve at least 300,000 tonnes of waste recovery and a social status value of 120 at the end of 2050. Another player will play as a PSO and their goal is to meet the scheme target and collect tokens of at least 200,000 by the end of 2050. Each player will be given 15,000 tokens at the start to pick their first set of cards. 


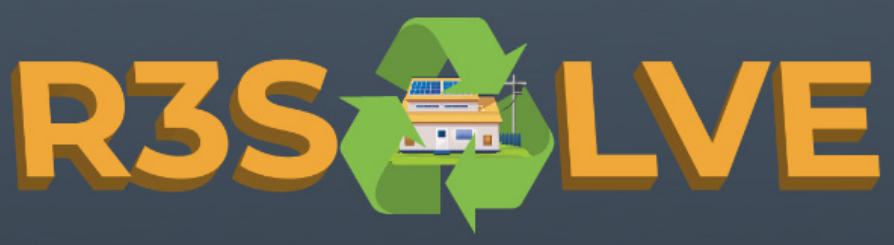

Room Code: DHSCS
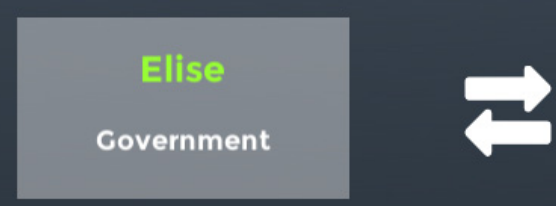

\section{Steven}

Product Stewardship

Leave Game

Start Game

Figure 6. Multiplayer lobby.

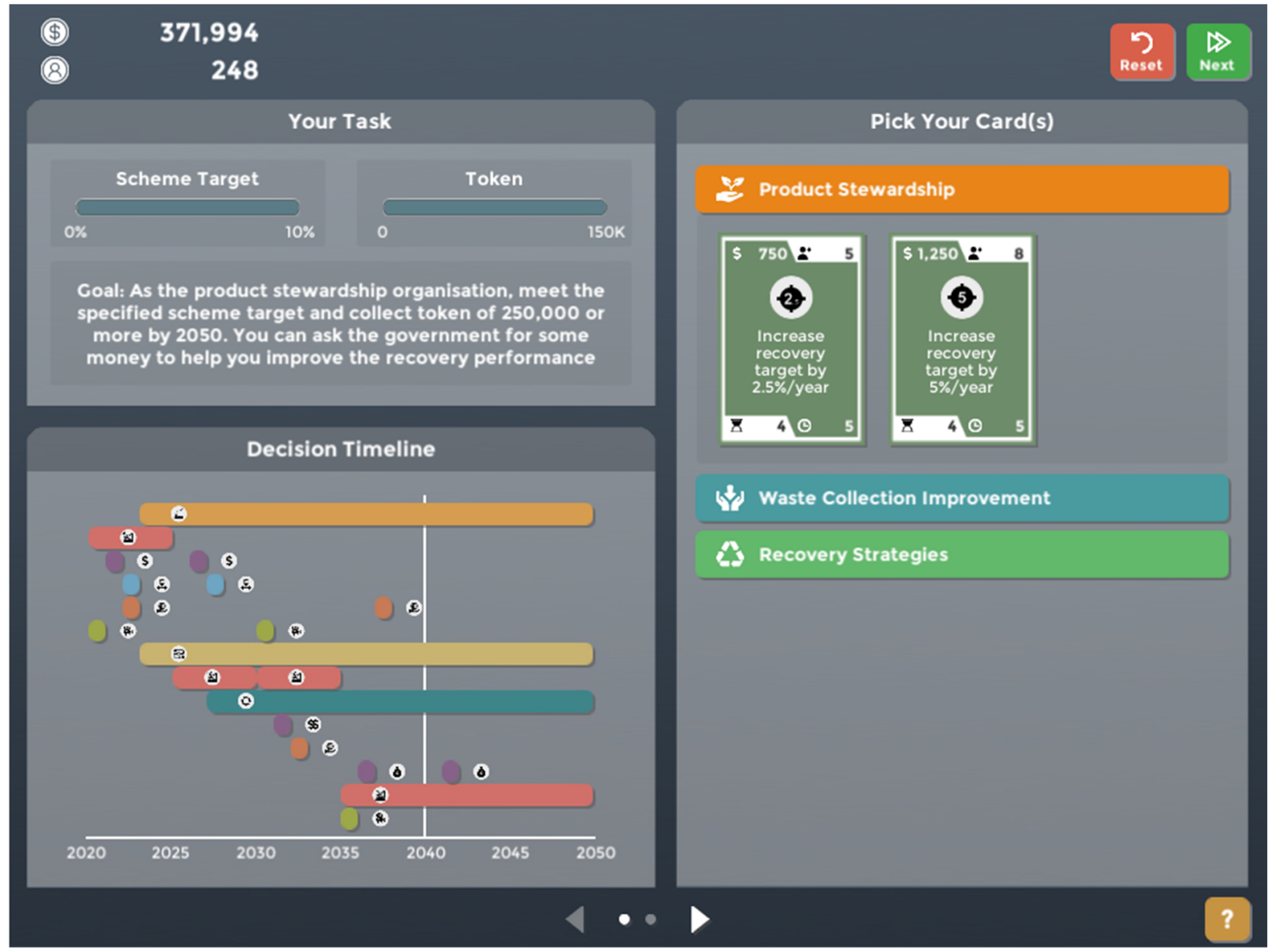

Figure 7. Multiplayer game session-main page. 
Decision-making: The government can set the product stewardship approach, landfill levy or ban, and funding model. An additional decision in this mode is the ability of the government player to provide PSO with industry grants to support their investment. The PSO can improve waste collection improvement through promotions, improve the accessibility of collection points, reuse strategy, and material recovery rate improvement. The scheme target is determined by the PSO if the agreed scheme is an industry-led or voluntary approach. Otherwise, the government will define the scheme target.

Turn-based system: In this mode, the KEE was extended to include a module where two players with different properties can interact with each other. The decision timeline, game summary, and detailed simulation results' interfaces will be shared across all clients to enable all players to view each other's decisions and results. The game was designed where the government player is responsible to make the first turn. The PSO player will have to wait for the government player to complete their turn and act in response to their actions. Actions from each player will be sent to the PUN's server and distributed across the database in all clients in the same game room.

Rewards and penalties: Rewards were calculated differently for each player in this mode. PSO token earning for each round is calculated using Equation (3), which is $70 \%$ of the tokens generated from the recovered materials. Government token earning is calculated using Equation (4), which accounts for 30\% as a fraction of tax from tokens from recovered materials. Penalties were calculated similarly to the single player mode (Equation (2)) where non-compliance to the scheme target and landfill disposal were used as its indicators. However, penalties only directly apply to PSO players.

$$
\begin{gathered}
\text { PSO token earning }=\text { token earning }-(0.3 \times \text { token earning }) \\
\text { government token earning }=\text { token earning }- \text { PSO token earning }
\end{gathered}
$$

\subsection{Preliminary Game Evaluation}

The preliminary game evaluation indicates how well the game is perceived by experts and non-experts. This is not a conclusive outcome as this preliminary evaluation provided the authors with some insights on how well the game is received by players before deploying it to the stakeholders. Firstly, an evaluation was performed to measure how well players perceived the game. The result presented in Figure 8 indicates a positive reception from players, mostly because the goal, rules, and complexity of the game were effectively conveyed in the game. During the sessions, participants also mentioned that the game was a fun activity.

5. I would like to play the game again

4. The game was fun

3. The complexity of the game was good

2. The rules of the game were clear

1. The goal of the game was clear
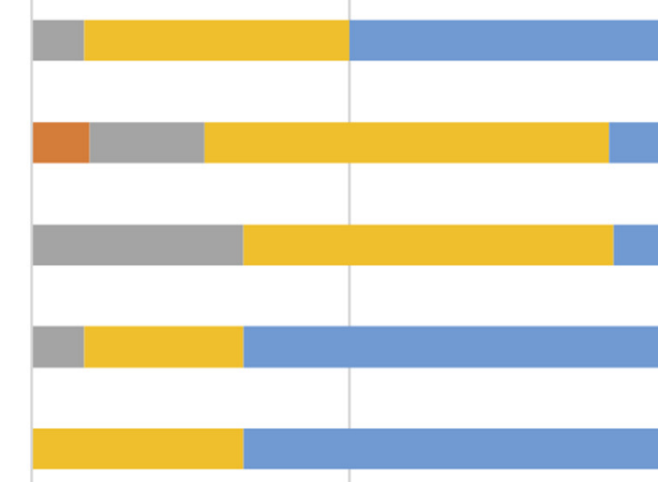

$\mu: 1.67, \sigma: 0.49$

$\mu: 1.42, \sigma: 0.67$

$\mu: 0.83, \sigma: 0.83$

$\mu: 0.75, \sigma: 0.62$

$\mu: 1.58, \sigma: 0.67$

$0 \%$

$50 \%$

$100 \%$

घtrongly Disagree $\square$ Disagree $\square$ Neutral $\square$ Agree $\square$ Strongly Agree

Figure 8. Players' overall impression of the game. 
The second evaluation concerns the cognitive and relational learning outcomes of the game (Figure 9). The measurement indicates how well the game can assist participants in understanding the complex problem and help to improve their decision-making ability in enabling circular economy strategies for solar panel waste. The game has favourable cognitive learning outcomes, particularly insights related to PV product stewardship, roles of and conflicts between stakeholders, and how the game can be used in a decision-making situation. Participants slightly disagreed that their relational learning outcomes have improved. This aspect is mainly related to how the game can convey the communication between the two players within the virtual environment.

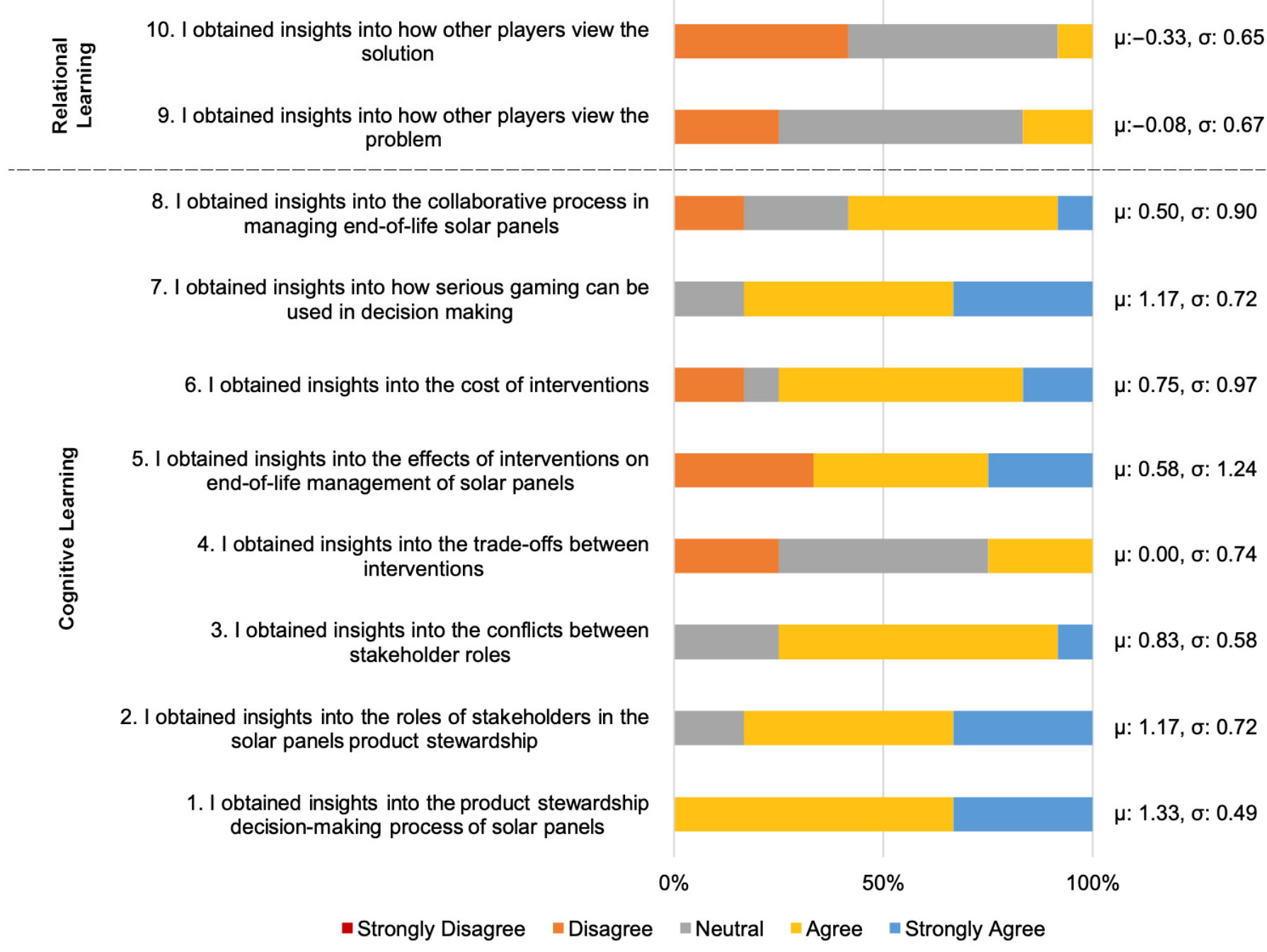

Figure 9. Learning outcomes of the game.

\section{Discussion}

The learning objectives of R3SOLVE align strongly with the current Australian government priorities in enabling the product stewardship scheme for PV panels and building its domestic recycling capability and capacity to deal with this waste stream [4]. The concept of product stewardship is not new; however, different products have distinct supply chain characteristics which necessitate different scheme designs. A few state governments have also been pushing this agenda by enabling a landfill levy or ban $[1,44]$ and/or industry grants to promote research and development (R\&D) [34]. Although an assessment process has been conducted by Sustainability Victoria on behalf of the federal government, the government has not been able to derive a scheme design that is sustainable due to the lack of modelling efforts. The game can potentially facilitate this process to create an 
understanding of the systemic impacts and derive an appropriate scheme design. It is expected that the multiplayer mode has more engagement impacts on stakeholders as it better conveys the collaborative and negotiation aspects between the government and PSO [45-47]. The single player game is more suitable for education and training to provide a holistic insight on the EoL management of PV panels and the roles and responsibilities of respective stakeholders in the supply chain [17].

Only a few immature PV recycling industries exist in Australia, whereas PV installations are geographically dispersed throughout the country $[1,48]$. This game can serve as a platform for existing PV recycling industries to understand the impacts of different waste collection improvement and recovery strategies and infrastructure development to achieve the scheme target and assess their profitability. Although the game did not capture the net present value (NPV) of their investment, it gives recycling industries an idea of how much waste will be generated in a particular year and the amount of PV panels that can be collected given a set of strategies that they implement.

The game summary and detailed simulation results in the game will help players to understand the strategies that form their rewards and penalties in the game. Rewards and penalties have been reported as having positive impacts on players' extrinsic motivation to achieve the best possible outcomes [49]. This feature is part of the game's narrative and player feedback system by confronting them with the direct consequences of their actions [50]. Understanding these direct consequences is part of the experiential and social learning process to improve stakeholders' decision-making abilities. In the multiplayer mode, players can discuss the results, rewards, and penalties throughout the game session to improve their collaboration skills.

Participants viewed the game positively and wanted to play the game again, which indicates the game's capability to increase learning motivations and engagement. The preliminary evaluation of the multiplayer game's learning outcomes indicates that the game is generally effective in assisting decision-making activities for enabling a PV product stewardship scheme, although it is lacking in the relational learning aspect. This could be a future area of improvement for the game to develop a feature that could facilitate better communication between the two players.

Globally, this game could potentially also aid other countries conducting similar efforts by increasing stakeholders' understanding of strategies to enable a product stewardship scheme for PV panels and their long-term impacts. Although the results may not reflect their actual conditions due to the use of the Australian residential solar sector used as the game's case study, stakeholders can still improve their cognitive and relational learning [9, 51]. The concept of product stewardship strongly aligns with the extended producer responsibility (EPR) principles applied in European countries and the United States [52,53]. Landfill levy or ban is also a universally accepted regulation in many countries to prevent waste from entering the landfill.

The limitation that this game has is the exclusive use of rewards and penalties and performance graphs as the gamification techniques. Employing a rewards and penalties system creates awareness around behaviours or actions that are encouraged and discouraged when solving a problem [49]. Displaying performance graphs have also been proven useful to increase learning motivation that focuses on continual improvement [54]. Other gamification techniques such as badges and leaderboards could also be useful in future sustainability-related serious games. These features have been applied extensively in serious games for education but can also potentially be useful in promoting stakeholder motivations and engagement $[55,56]$. Because the nature of this game is not competitive, but rather collaborative, we hypothesised that employing such techniques will likely be counterproductive to the outcomes. Nonetheless, an insight on gamification techniques can be drawn after the game has been evaluated by stakeholders as to whether such features have satisfied the purpose of the game. 


\section{Conclusions and Future Directions}

A serious game called R3SOLVE was developed in this study to improve understanding and stakeholders' decision-making ability in enabling EoL management of PV panels. The game consisted of a single player mode and multiplayer mode. It was built based on an integrated design framework that includes a formative and summative evaluation process to ensure that the game is engaging and realistic. It consisted of a KEE (i.e., SD model and game database) as the decision support system for the game and a UI, which are connected through a communication controller, PUN, events controller, and simulation and decision controller. By incorporating an SD model that was developed using a participatory approach, the game can convey system complexity, dynamic behaviour, and accurate representation of the real-world problem. The beta testing process also helped to improve learning the objectives of the game, user experience, and to identify bugs before the deployment for stakeholders' use.

The learning objectives of the game is for stakeholders (i.e., government and PSO) to learn about the concept of the PV product stewardship scheme and its supporting decisions, such as landfill regulation, waste collection improvement strategies, and recovery strategies. The cyclical design of the game will enable players to have direct feedback based on their actions as a reference to take further actions. Rewards and penalties are also employed to increase players' extrinsic motivation to use critical thinking in making decisions and achieving the best outcomes in the game. Performance graphs are utilised to measure and visualise player performance over time.

Given that this study is only limited to describing the serious game development process (i.e., formative evaluation), future studies should focus on conducting a workshop session with stakeholders consisting of the government and recycling industries. This will facilitate dialogue and discussion among stakeholders to design a PV product stewardship scheme and plan the collection and recycling strategies and infrastructure development. Stakeholders can also provide inputs to the authors to further improve the effectiveness of the game. The workshop should also evaluate cognitive and relational learning outcomes to understand the role of the developed serious game in promoting stakeholders' understanding and decision-making ability. Future game development in EoL management of PV panels should also incorporate spatial scales to enable more accurate decision experimentation given that different Australian states or countries have different PV uptake and socio-economic and political characteristics. More broadly, future sustainability-related serious games can integrate other gamification techniques (e.g., badges and leaderboards) to promote better stakeholder engagement and motivations.

Author Contributions: Conceptualization, H.S.; methodology, H.S. and B.S.; software, H.S.; validation, H.S.; resources, H.S.; data curation, H.S.; formal analysis, H.S. and B.S.; writing-original draft preparation, H.S.; writing-review and editing, R.A.S., O.S. and M.D.; visualization, H.S.; supervision, R.A.S., O.S. and M.D.; project administration, R.A.S. and O.S. All authors have read and agreed to the published version of the manuscript.

Funding: This research received no external funding. The APC was partially funded by Griffith University.

Institutional Review Board Statement: The study was conducted according to the Griffith University Research Ethics Manual, approved by the Griffith University Human Research Ethics team (GU Ref No. 2018/675).

Informed Consent Statement: Informed consent was obtained from all subjects involved in the study.

Data Availability Statement: Not applicable.

Acknowledgments: The authors would like to acknowledge all workshop participants who have provided inputs and feedbacks to improve the serious game. The authors would like to acknowledge the support provided by Australia and New Zealand (ANZRP) Ltd. to this research. The first author 
would also like to acknowledge Griffith University Postgraduate Research Scholarship (GUPRS) for funding this research project.

Conflicts of Interest: The authors declare no conflict of interest.

\section{References}

1. Salim, H.K.; Stewart, R.A.; Sahin, O.; Dudley, M. Dynamic modelling of Australian rooftop solar photovoltaic product stewardship transition. Waste Manag. 2021, 127, 18-29. [CrossRef]

2. Mahmoudi, S.; Huda, N.; Behnia, M. Photovoltaic waste assessment: Forecasting and screening of emerging waste in Australia. Resour. Conserv. Recyl. 2019, 146, 192-205. [CrossRef]

3. Appolloni, A.; D'Adamo, I.; Gastaldi, M.; Santibanez-Gonzalez, E.D.R.; Settembre-Blundo, D. Growing e-waste management risk awareness points towards new recycling scenarios: The view of the Big Four's youngest consultants. Environ. Technol. Innov. 2021, 23, 101716. [CrossRef]

4. Minister's Priority List 2021-22. Available online: https://www.environment.gov.au/protection/waste/product-stewardship/ ministers-priority-list/2021-22 (accessed on 1 July 2021).

5. Cartwright, S.J.; Bowgen, K.M.; Collop, C.; Hyder, K.; Nabe-Nielsen, J.; Stafford, R.; Stillman, R.A.; Thorpe, R.B.; Sibly, R.M. Communicating complex ecological models to non-scientist end users. Ecol. Model. 2016, 338, 51-59. [CrossRef]

6. Kahan, D.M.; Jenkins-Smith, H.; Braman, D. Cultural cognition of scientific consensus. J. Risk Res. 2011, 14, 147-174. [CrossRef]

7. Sušnik, J.; Chew, C.; Domingo, X.; Mereu, S.; Trabucco, A.; Evans, B.; Vamvakeridou-Lyroudia, L.; Savić, D.A.; Laspidou, C.; Brouwer, F. Multi-stakeholder development of a serious game to explore the water-energy-food-land-climate nexus: The SIM4NEXUS approach. Water 2018, 10, 139. [CrossRef]

8. van Hardeveld, H.A.; Driessen, P.P.J.; Schot, P.P.; Wassen, M.J. How interactive simulations can improve the support of environmental management-lessons from the Dutch peatlands. Environ. Model. Softw. 2019, 119, 135-146. [CrossRef]

9. den Haan, R.J.; van der Voort, M.C.; Baart, F.; Berends, K.D.; van den Berg, M.C.; Straatsma, W.; Geenen, A.J.P.; Hulscher, S.J.M.H. The Virtual River Game: Gaming using models to collaboratively explore river management complexity. Environ. Model. Softw. 2020, 134, 104855. [CrossRef]

10. Rodela, R.; Ligtenberg, A.; Bosma, R. Conceptualizing serious games as a learning-based intervention in the context of natural resources and environmental governance. Water 2019, 11, 245. [CrossRef]

11. Keijser, X.; Ripken, M.; Mayer, I.; Warmelink, H.; Abspoel, L.; Fairgrieve, R.; Paris, C. Stakeholder engagement in maritime spatial planning: The efficacy of a serious game approach. Water 2018, 10, 724. [CrossRef]

12. Mochizuki, J.; Magnuszewski, P.; Linnerooth-Bayer, J. Games for aiding stakeholder deliberation on nexus policy issues. In Managing Water, Soil and Waste Resources to Achieve Sustainable Development Goals: Monitoring and Implementation of Integrated Resources Management; Hülsmann, S., Ardakanian, R., Eds.; Springer: Cham, Switzerland, 2018.

13. Savic, D.A.; Morley, M.S.; Khoury, M. Serious gaming for water systems planning and management. Water 2016, 8, 456. [CrossRef]

14. Salim, H.K.; Stewart, R.A.; Sahin, O.; Dudley, M. End-of-life management of solar photovoltaic and battery energy storage systems: A stakeholder survey in Australia. Resour. Conserv. Recycl. 2019, 150, 104444. [CrossRef]

15. Flood, S.; Cradock-Henry, N.A.; Blackett, P.; Edwards, P. Adaptive and interactive climate futures: Systematic review of 'serious games' for engagement and decision-making. Environ. Res. Lett. 2018, 13, 63005. [CrossRef]

16. Sterman, J.D. Business Dynamics: Systems Thinking and Modeling for a Complex World; McGraw-Hill: Boston, MA, USA, 2000.

17. Stanitas, M.; Kirytopoulous, K.; Vareilles, E. Facilitating sustainability transition through serious games: A systematic literature review. J. Clean. Prod. 2019, 208, 924-936. [CrossRef]

18. Madani, K.; Pierce, T.W.; Mirchi, A. Serious games on environmental management. Sustain. Cities Soc. 2017, 29, 1-11. [CrossRef]

19. Hirose, Y.; Sugiura, J.; Shimomoto, K. Industrial waste management simulation game and its educational effect. J. Mater. Cycles Waste. 2004, 6, 58-63. [CrossRef]

20. Cuccurullo, S.; Francese, R.; Passero, I.; Tortora, G. A 3D serious city building game on waste disposal. Int. J. Distance Educ. Technol. 2015, 11, 8. [CrossRef]

21. Destyanto, A.R.; Fajar, N.F.; Ardi, R. Serious simulation game design to support extensive understanding of closed-loop supply chain concept in e-waste management context. In Proceedings of the 5th International Conference on Industrial and Business Engienering, Hong Kong, China, 27-29 September 2019; pp. 101-105.

22. Wu, K.-C.; Huang, P.-Y. Treatment of an anonymous recipient: Solid-waste management simulation game. J. Educ. Comput. Res. 2015, 52, 568-600. [CrossRef]

23. Bassi, A.M.; De Rego, F.; Harrisson, J.; Lombardi, N. WATERSTORY ILE: A systemic approach to solve a long-lasting and far-reaching problem. Simulat. Gaming 2015, 46, 404-429. [CrossRef]

24. Richards, R.G.; Smith, C.; Setianto, N. Opening SESAMME: An iPad-based application for developing socio-ecological models. In Proceedings of the 21st International Congress on Modelling and Simulation, Gold Coast, QLD, Australia, 29 November-4 December 2015.

25. Khoury, M.; Gibson, M.J.; Savic, D.A.; Chen, A.S.; Vamvakeridou-Lyroudia, L.; Langford, H.; Wigley, S. A serious game designed to explore and understand the complexities of flood mitigation options in urban-rural catchments. Water 2018, 10, 1885. [CrossRef] 
26. Craven, J.; Angarita, H.; Corzo Perez, G.A.; Vasquez, D. Development and testing of a river basin management simulation game for integrated management of the Magdalena-Cauca river basin. Environ. Model. Softw. 2017, 90, 78-88. [CrossRef]

27. Neset, T.-S.; Andersson, L.; Uhrqvist, O.; Navarra, C. Serious gaming for climate adaptation-Assessing the potential and challenges of a digital serious game for urban climate adaptation. Sustainability 2020, 12, 1789. [CrossRef]

28. Neset, T.-S.; Juhola, S.; Wiréhn, L.; Käyhkö, J.; Navarra, C.; Asplund, T.; Glaas, E.; Wibeck, V.; Linnér, B.-O. Supporting dialogue and analysis on trade-offs in climate adaptation research with the Maladaptation Game. Simulat. Gaming 2020, 51, 378-399. [CrossRef]

29. Teague, A.; Sermet, Y.; Demir, I.; Muste, M. A collaborative serious game for water resources planning and hazard mitigation. Int. J. Disaster Risk Reduct. 2021, 53, 101977. [CrossRef]

30. Besiou, M.; Van Wassenhove, L.N. Closed-loop supply chains for photovoltaic panels: A case-based approach. J. Ind. Ecol. 2016, 20, 929-937. [CrossRef]

31. van Daalen, C.E.; Schaffernicht, M.; Mayer, I. System dynamics and serious games. In Proceedings of the International Conference of the System Dynamics Society, Delft, The Netherlands, 20-24 July 2014; pp. 1-26.

32. Braad, E.; Žavcer, G.; Sandovar, A. Processes and models for serious game design and development. In Entertainment Computing and Serious Games; Lecture Notes in Computer Science; Dörner, R., Göbel, S., Kickmeier-Rust, M., Masuch, M., Zweig, K., Eds.; Springer: Cham, Switzerland, 2016; Volume 9970, pp. 92-118.

33. Myrovali, G.; Tsaples, G.; Morfoulaki, M.; Aifadopoulou, G.; Papathanasiou, J. An interactive learning environment based on system dynamics methodology for sustainable mobility challenges communication \& citizens' engagement. In Proceedings of the International Conference on Decision Support System Technology 2018, Heraklion, Greece, 22-25 May 2018; pp. 88-99.

34. Salim, H.K.; Stewart, R.A.; Sahin, O.; Dudley, M. Systems approach to end-of-life management of residential photovoltaic panels and battery energy storage system in Australia. Renew. Sustain. Energy Rev. 2020, 134, 110176. [CrossRef]

35. Clean Energy Council. Clean Energy Australia Report 2021. Available online: https://assets.cleanenergycouncil.org.au/ documents/resources/reports/clean-energy-australia/clean-energy-australia-report-2021.pdf (accessed on 5 July 2021).

36. Forrester, J.W.; Senge, P.M. Tests for building confidence in system dynamics models. TIMS Stud. Manag. Sci. 1980, 14, 209-228.

37. Photon. PUN. Available online: https://www.photonengine.com/pun (accessed on 7 July 2021).

38. Shi, Y.; Du, J.; Lavy, S.; Zhao, D. A multiuser shared virtual environment for facility management. Proceed. Eng. 2016, 145, 120-127. [CrossRef]

39. Mariais, C.; Michau, F.; Pernin, J.-P. A description grid to support the design of learning role-play games. Simulat. Gaming 2012, 43, 23-33. [CrossRef]

40. Ávila-Pesántez, D.; Rivera, L.A.; Alban, M.S. Approaches for serious game design: A systematic literature review. Comput. Educ. J. 2017, 8, 1-11.

41. Nadolski, R.J.; Hummel, H.G.; Van Den Brink, H.J.; Hoefakker, R.E.; Slootmaker, A.; Kurvers, H.J.; Storm, J. EMERGO: A methodology and toolkit for developing serious games in higher education. Simulat. Gaming 2008, 39, 338-352. [CrossRef]

42. Unity. Event System. Available online: https://docs.unity3d.com/Packages/com.unity.ugui@1.0/manual/EventSystem.html (accessed on 8 July 2021).

43. Chen, M.; Downing, L. Using simulations to enhance students' learning in management accounting. J. Hosp. Tour. Educ. 2006, 18, 27-32. [CrossRef]

44. King, S.; Boxall, N.J. Lithium battery recycling in Australia: Defining the status and identifying opportunities for the development of a new industry. J. Clean. Prod. 2019, 215, 1279-1287. [CrossRef]

45. Harteveld, C.; Bekebrede, G. Learning in single- versus multiplayer games: The more the merrier? Simulat. Gaming 2011, 42, 43-63. [CrossRef]

46. Wendel, V.; Gutjahr, M.; Göbel, S.; Steinmetz, R. Designing collaborative multiplayer serious games. Educ. Inf. Technol. 2013, 18, 287-308. [CrossRef]

47. Saitua-Iribar, A.; Corral-Lage, J.; Peña-Miguel, N. Improving knowledge about the sustainable development goals through a collaborative learning methodology and serious game. Sustainability 2020, 12, 6169. [CrossRef]

48. Majewski, P.; Al-shammari, W.; Dudley, M.; Jit, J.; Lee, S.-H.; Myoung-Kug, K.; Sung-Jim, K. Recycling of solar PV panels- product stewardship and regulatory approaches. Energy Policy 2021, 149, 112062. [CrossRef]

49. Morganti, L.; Pallavicini, F.; Cadel, E.; Candelieri, A.; Archetti, F.; Mantovani, F. Gaming for Earth: Serious games and gamification to engage consumers in pro-environmental behaviours for energy efficiency. Energy Res. Soc. Sci. 2017, 29, 95-102. [CrossRef]

50. Westera, W. Why and how serious games can become far more effective: Accommodating productive learning experiences, learner motivation and the monitoring of learning gains. J. Educ. Technol. Soc. 2019, 22, 59-69.

51. de Kraker, J.; Offermans, A.; van der Wal, M.M. Game-based social learning for socially sustainable water management. Sustainability 2021, 13, 4646. [CrossRef]

52. Lane, R.; Watson, M. Stewardship of things: The radical potential of product stewardship for re-framing responsibilities and relationships to products and materials. Geoforum 2012, 43, 1254-1265. [CrossRef]

53. Wagner, T.P. Examining the concept of convenient collection: An application to extended producer responsibility and product stewardship frameworks. Waste Manag. 2013, 33, 499-507. [CrossRef]

54. Sailer, M.; Hense, J.U.; Mayr, S.K.; Mandl, H. How gamification motivates: An experimental study of the effects of specific game design elements on psychological need satisfaction. Comput. Hum. Behav. 2017, 69, 371-380. [CrossRef] 
55. Robson, K.; Plangger, K.; Kietzmann, J.H.; McCarthy, I.; Pitt, L. Game on: Engaging customers and employees through gamification. Bus. Horiz. 2016, 59, 29-36. [CrossRef]

56. Ponce, P.; Meier, A.; Méndez, J.I.; Peffer, T.; Molina, A.; Mata, O. Tailored gamification and serious game framework based on fuzzy logic for saving energy in connected thermostats. J. Clean. Prod. 2020, 262, 121167. [CrossRef] 